\title{
NETWORKING ON THE UTILIZATION OF LOCAL NATURAL RESOURCES
}

\author{
Katalin Herbály-Hekli
}

\author{
Szolnok College, 5000 Szolnok, Tiszaligeti sétány
}

\begin{abstract}
Together with its partners, Szolnok College is planning to evaluate a new project for networking on the utilization of local natural resources. This project is based on a research work (using the findings of the surveys completed by the representatives of hosts living in the eastern part of Hungary).

The project itself is based on the adaptation of the theory of tourism into practice by presenting existing natural values in the supply portfolio of tourist service providers. A unique natural environment can be found alongside a $120 \mathrm{~km}$-long stretch of River Tisza. These natural values interlink and complete each other with respect to Lake Tisza and River Tisza. Regions and settlements situated further from the specified settlements are also rich in natural values which guests will definitely be pleased to get acquainted with. The six landscape centres (including LHH regions) alongside river Tisza (in the two regions) symbolise the interdependent system of the sample area of the project while a single landscape centre in the Pásztó Minor Region embodies a unique character.

A register will be prepared for each landscape centre containing unique natural values that can be involved in the tourist supply and handicraft/economic activities (e.g. basket weaving, floodplain economy) that are or can be built on these natural values.

A pictorial English/German-Hungarian professional dictionary summarises the distinctive nature of landscape centres.

The education material demonstrating the registers is going to be developed both in conventional and electronic form; its spatial IT appearance on the Internet is considered a special feature. The education material will be supplemented with other information currently missing such as those related to environmentally friendly economy, and the legal context.

The methodology allows the adaptation of the method in other regions, even in the whole country.

The new qualifying and benchmarking system and the trademark managed by a profession-specific cluster that strengthens network co-operation and controls the development guarantee the achievement of high quality tourism.
\end{abstract}

Key words: networking, cluster, register of unique natural values and handicraft/economic activities

\section{Introduction}

The regions of the North Plain and Northern Hungary have rich natural resources, of which only a small proportion has been utilised intensively in tourism and has acquired the required reputation accordingly (e.g. Hortobágy, the Aggtelek Karst). Besides natural resources, the two regions have significant farming and cultural traditions as well (e.g. overbank farming, pottery), of which the involvement in the offer for tourists is still low.

The actors and professional organisations of the tourism market do not have extensive information on the values mentioned above (which already exist in their microenvironment) and on the method of their sustainable utilisation. The representation and further utilisation of existing good examples - national and foreign best practices - (e.g. in education) are also unsatisfactory.

The role of the institutions of higher education that can be found in the above mentioned regions is especially important from the point of view of teaching the young experts e.g. in the field of tourism. Szolnok College represents one of those institutions that try to involve students in different research work and in working out projects for different applications, connected to tourism.

This paper contains the results of a research work (based on the assessment of the surveys carried out by the students) and of a project using partly the findings of this research process.

\section{Material studied}

\subsection{Research work}

The research work was about getting information on the work and opinion of the hosts living in the settlements, where our students came from, in the eastern part of Hungary. (So the results were not representative but gave useful information to students and to the teachers about the way of thinking of the hosts, as well. Table 1.)

This paper highlights only three of the questions that are mostly related to the aims of the project below. The hosts were asked whether they could mention some reasons that made their settlements and its surroundings attractive. 
Table 1. Denomination of the counties

\begin{tabular}{|l|c|c|}
\hline County & $\begin{array}{c}\text { Number of hosts } \\
\text { (person) }\end{array}$ & $\begin{array}{c}\text { Number of hosts } \\
(\mathbf{\%})\end{array}$ \\
\hline Jász-Nagykun-Szolnok & 21 & 53,85 \\
\hline Békés & 6 & 15,38 \\
\hline Szabolcs-Szatmár-Bereg & 2 & 5,13 \\
\hline Heves & 2 & 5,13 \\
\hline Csongrád & 1 & 2,56 \\
\hline Hajdú-Bihar & 4 & 10,26 \\
\hline Pest & 2 & 5,13 \\
\hline Borsod-Abaúj-Zemplén & 1 & 2,56 \\
\hline Altogether & $\mathbf{3 9}$ & $\mathbf{1 0 0}$ \\
\hline
\end{tabular}

Resource: surveys

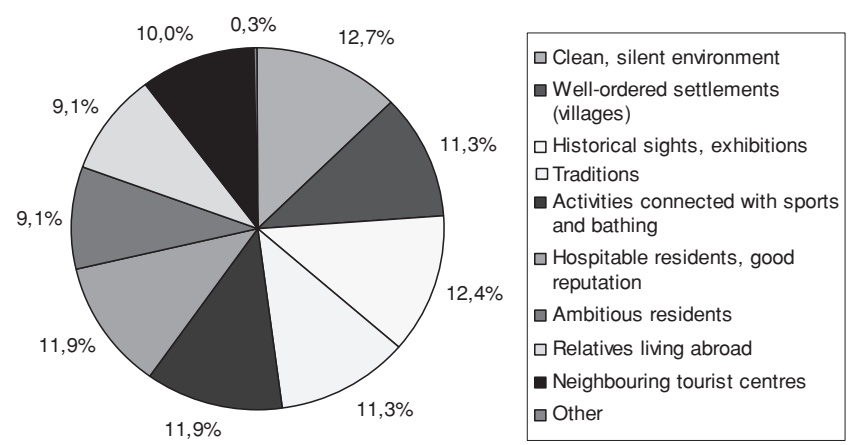

Figure 1. Attractive values of the settlements and their surroundings Resource: surveys

Figure 1 shows that (in most cases the rural) settlements and their environment, the traditions and the existing tourist centres can be mentioned as the elements of the desirable tourist supply. It is obvious that a varied range of the natural environment and traditional activities, existing even in our days, could be involved in the tourism supply in the eastern part of Hungary.

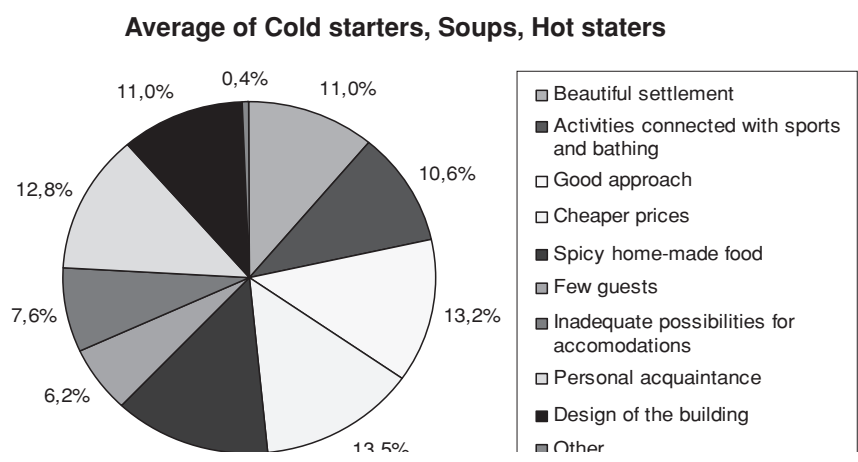

Figure 2. Reasons why tourists visit the settlements in question Resource: surveys

Figure 2 gives information on the hosts'/tourist service providers' opinion on the reasons why tourists visit their settlements and choose the accommodation offered by them. Some elements of the region's values can be found as the most important factors (activities connected with sports and bathing, home-made food, beautiful settlements, etc.)

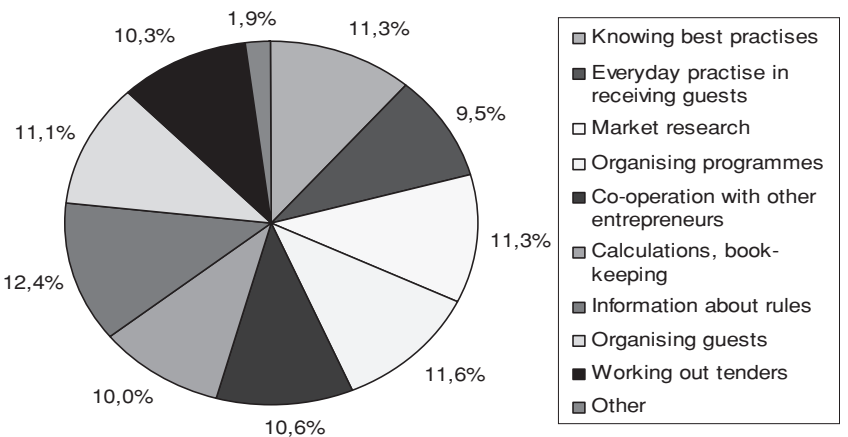

Figure 3. List of activities, hosts need help in Resource: surveys

We wanted to get some information on the activities that they need help in. We got the list of the most common answers, like learning about the experiences of others in the given field, market research, organising programmes, co-operating with others etc. (Figure 3 ) The findings of this question prove the importance of networking and taking part in different training programmes (about getting the latest information on the legal regulations, best practises, tenders, etc.) in the future

\section{Area description}

\subsection{The planned project}

After all the answers of the survey have been analysed, we found an application for planning teaching programmes and tourism destination related to tourism hospitality in the North Hungarian and North Plain Regions.

In preparing the project for the application we used the results of the above-mentioned research work, while $76.92 \%$ of the surveys were completed in the counties, belonging to these two regions.

The regions forming the focal areas of the project are among the most depressed regions of Hungary in terms of social and economic levels. Several LHH small regions and settlements can be found in the regions.

\subsubsection{Project objective}

The basic objective of the project is the development of sustainable tourism - especially eco-, and rural tourism - and the enhancement of its weight and competitiveness in the given regions. The employees of these two areas obviously work in regional settlements, thus the project contributes to narrowing the economic and social disparities between the developing urban centres and the rural (peripheral regional) areas as well as between Hungary and the more developed countries of the EU in general.

The project fully fits into the international, national, regional, county, small regional and local development and touristic strategies. The most important of these are: National Strategic Reference Budget, National Tourism Development 
Strategy, Development Concept and Strategic Programme of the North Plain Region, Eco-Tourism Strategy and the Strategy of Tourism of Lake Tisza.

Practically, all the above designate the development of eco-, and rural tourism as a priority / highlighted area including the development of attractions, infrastructure, services, marketing and the organisational framework. All activities to be completed within the framework of the project are included in the areas of development directly or indirectly.

Finally, the objective of the project can be summarised as the enhancement of sustainable development together with its economic and social dimensions. It shall enhance the participants' environmental awareness, the active protection of environmental and natural values, the possible access to and quality of environmental information; unemployment shall decrease in the region; the competitiveness of the region and the number of the participants in the field of tourism shall increase. Partners shall undertake the protection of the quality of environment, establishment and operation of cooperation forums, and effective social participation during their implementation.

\subsubsection{Project description}

All the above-mentioned facts justify that the service providers of tourism and the dispersedly operating economic actors should co-operate to become organised in a professionspecific cluster (mostly in the area of rural eco-tourism). Therefore the enhancement of the information level of the market actors is justified by means of the transfer of practical knowledge (trainings, e-learning, conferences, websites, etc.)

Tasks to be solved (with the participation of the students of Szolnok College):

- Mapping of elements existing in the two regions and linked to the utilisation of local natural resources and their involvement in the offer for tourists (in the form of cadastre to be elaborated) and the development of related methodology and standards.

- Introduction of services, display areas and programmes available in the rural regions, development of the basic technical infrastructure of rural events.

- Generalisation of the professional qualification of accommodations of rural tourism. Beyond the nationally accepted "sunflower" evaluation system the union of enterprises operating in the sector must be created within the regional framework by means of establishing a rural cluster for example. A regional quality assurance and evaluation system can be developed for the categorisation and specialisation of accommodation, such as a manor of craftsmanship, tradition preservation or organic farming.

- Strengthening of professional NGO-s and organisations facilitating sales, support of the establishment of an integrator system for selling products.

- Organisation of education, training, in-service training in the form of short courses (knowledge-transfer for hosts, vocabulary of terms in foreign languages, communication, etc.), as well as successful examples by sharing the mutual experiences of organisations operating in tourism and connecting to other training programmes (e.g. house of knowledge) to be built into school education (e.g. familiarisation with traditions and their preservation), etc.

\subsubsection{Public relations}

It is necessary to elaborate and implement a PR and marketing plan with the following activities:

- Continuous liaison with printed and electronic media in the region of the project. Targets are: introduction to the work of organisers, activation of service providers, exposition of the project result, exposition of donors and the programme.

- Press conferences are a substantial part of this work. Opening and closing conference are important elements of dissemination.

- Use of Internet accessible for the wide public is especially important (e.g. homepage, links to the partners).

- Forums must be organised for the service providers of tourism, the municipalities, the public at large, within the frame of which the results obtained during implementation can also be disclosed.

- The curriculum to be elaborated is suitable for disclosing new pieces of information both independently and by means of utilisation in education.

- Implemented systems, registers increasing competitiveness and serving the accomplishment of quality tourism / Completed evaluations (impact of the project, further activities, development possibilities)

\subsubsection{Target groups}

It is important to list the target groups that can make use of the project, e.g.:

- Touristic SME-s applying (or intending to apply) aspects of sustainability and ecological view in the focal area (e.g. landlords, programme organisers, tourism entrepreneurs), employees of attractions

- Colleagues of NGO-s and organisations of touristic profile acting in the focal area

- Actors of the market of tourism interested in sustainable aspects and ecological view (e.g. landlords, programme organisers, touristic entrepreneurs, hotels)

- Colleagues of touristic SME-s, NGO-s and organisations of touristic profile interested in cooperation

- Colleagues of SME-s, NGO-s and (e.g. educational) institutions who facilitate and wish to apply the systems serving the implementation of quality tourism.

\section{Results}

The paragraphs below show the most important results (activities that we want to implement) in the future: 
- An attitude-forming complex communication campaign serving the conceptual and framework system of sustainable tourism that supports the objectives and dissemination of the project in details, not only on the sample area. Professional events (e.g. campaign, conference and presentation), marketing and communication plan (articles, publications and website) for the purpose of improving the professional knowledge and guest-friendly attitude of tourist service providers.

- Compilation of a specific appeal register for the six landscape centres (completed by a seventh one in the Pásztó Region) alongside the $120 \mathrm{~km}$ stretch of River Tisza (discovering and systemizing tourist spectacles based on local natural, landscaping and settlement values) that contains unique natural values that can be involved in the tourist supply and handicraft /economic activities (e.g. basket weaving, floodplain economy) that are or can be built on these natural values.

- The education material will be supplemented with other information currently missing such as those related to environment friendly economy and the legal context. The education material demonstrating the registers is going to be developed both in conventional and electronic form (eLearning, spatial IT display); its spatial IT appearance allows for special display on the Internet.

- Preparation of a pictorial English/German-Hungarian professional dictionary that lists the spectacles of landscape centres.

- Organization and accomplishment of an educational series and training both online (eLearning) and in the designated decentres using the education materials being worked on.

- Development of a methodology that allows for the adaptation of the method in other land units.
- Foundation of a new qualifying and benchmarking servicing system that serves the accomplishment of high-standard tourism and increases the competitiveness of tourist participants, and a new tourist trademark. Organization and implementation of a profession-specific tourist cluster, for tourist service providers, that strengthens network co-operation and controls practical and trainee exchange (domestic and international) and educational and consultation programmes.

\section{Conclusion}

One of the main results of the paper is to show the importance and effectiveness of involving students in research work and analysis. Their work is useful for their studies and practical training and can be used as a background (see above) for other development work.

The project itself enhances the offer portfolio of tourism service providers by revealing the provincial (natural, economic) values existing in the two regions (not yet used in tourism), by elaborating the utilisation of craftsmanship, increases the force of retaining guests, and stimulates their satisfaction by applying sustainable tourism. It may facilitate the involvement in tourism of a larger sphere of actors and enhance their competitiveness. The register, methodology and vocabulary can serve as a model due to its originality; its results can applied and adapted in other domestic and foreign regions as well. The cluster gives a real possibility for continuous networking.

We hope that having been completed the project can serve its general aim - in the field of tourism - of Hungary that (with the participation of well-trained experts) is to provide exclusive tourism supply for our present and potential guests. 